\title{
Associative priming in color naming: Interference and facilitation
}

\author{
JENNIFER S. BURT \\ University of Queensland, Brisbane, Queensland, Australia
}

\begin{abstract}
In Experiment 1, color-naming interference for target stimuli following associated primes was greater in a group making a lexical decision to the prime than in a group reading the prime silently. Highfrequency targets were responded to more quickly than low-frequency targets. In Experiment 2, with subjects naming the prime, there was evidence of associative interference when the prime and the target were grouped temporally but not when the intertrial interval was comparable with the prime-target interval. Associative primes presented at a short (120-msec) prime-target stimulus onset asynchrony facilitated color naming in Experiment 3. Taken together, the results suggest that the effect of faster processing of the base word in a color-naming task is facilitatory and that color-naming priming interference arises when associative prime processing increases conflict between word and color responses by enhancing phonological or articulatory activation of the base word.
\end{abstract}

The Stroop color-naming interference effect (see the review by C. M. MacLeod, 1991; Stroop, 1935) demonstrates a failure of selective attention, in that subjects asked to name the color of a word's print are unable to ignore the incongruent information provided, for example, by the word blue in red lettering. The tendency of skilled readers to read the word (hereafter termed the base word), even when asked to ignore it, was exploited in a noncolor word version of the Stroop test by Warren $(1972,1974)$, who used color-naming latencies as indices of the effects of variables on visual word recognition. Because word reading is not required for color naming, effects on colornaming latencies in the noncolor word Stroop are assumed to be uncontaminated by strategies directed toward identification of the base word (cf. Tanenhaus, Flanigan, \& Seidenberg, 1980). This is a significant advantage of the noncolor word Stroop task as a tool for investigating lexical access in visual word recognition, in light of the evidence for the effects of various task-specific strategies that may qualify the interpretation of data from lexical decision (e.g., Balota \& Chumbley, 1984) and naming tasks (Andrews, 1989). However, there are several findings that cast doubt on the traditional interpretation of color-naming latencies in the noncolor word Stroop task. The purpose of the present work was to clarify the interpretation of this task in relation to associative priming.

The results of Experiment 2 were presented at the Twenty-second Experimental Psychology Conference at Brisbane, QLD, Australia, 1995. The research was supported by a University of Queensland Special Projects Grant. Part of the data for Experiment 2 were collected by Susan Ryan for a psychology undergraduate project. I thank Bob Lorch for guidance beyond expectations, Veronica Dark and an anonymous reviewer for helpful feedback on earlier versions of the paper, and Karin Humphreys for data collection. Correspondence concerning this article should be addressed to J. S. Burt, School of Psychology, University of Queensland, QLD 4072, Australia (e-mail: j.burt@psy.uq.edu.au).
In the studies by Warren $(1972,1974)$, the base word was the target in an associative priming arrangement. An associatively related or unrelated prime word was presented auditorily or visually (in white letters) prior to the target. It was demonstrated that an associatively related prime (e.g., king) increased the color-naming interference for the target (queen) above that observed with an unrelated prime (rose). The fact that priming was evident as facilitation in lexical decision and naming but as interference in color naming was explained by Warren in terms of competition between the activated word pronunciation and the color name. Specifically, within a framework provided by Morton's (1969) logogen model, Warren supposed that the relative rate of activation of the logogens for the base word and its color determined the relative speed of preparation of the color name and the base-word pronunciation. Further, the articulation programs for each vocal response must pass through a response buffer whose capacity is limited to one program at a time. The associative prime was thought to increase the probability that the word response would become available in the response buffer before the color response, with a consequent delay in color naming while the response buffer was cleared. Thus, an essential component of Warren's account is the relative speed of color and word processes, as in the horse race model of color-naming interference in the standard, color word Stroop task (see C. M. MacLeod, 1991).

Color-naming interference by associative primes in the noncolor word Stroop task has been replicated (Henik, Friedrich, \& Kellogg, 1983; Parkin, 1979) and, in addition, has been established in priming of category exemplars by category names (Warren, 1972), contextual priming in sentences (Merrill, Sperber, \& McCauley, 1981; Whitney, McKay, Kellas, \& Emerson, 1985), and priming of one meaning of polysemous words (Conrad, 1974; Oden \& Spira, 1983). Furthermore, in a list-reading paradigm, where subjects were instructed to ignore the printed words, 
Klein (1964) observed that color naming was faster for trials involving one of four very rare words ( $\mathrm{sol}$, belot, eft, abjure) than for those involving one of four common words (put, heart, take, friend). These findings are consistent with the proposal that retardation of color naming is a consequence of faster processing of the base word.

However, there are a number of results from the noncolor word Stroop task that challenge the traditional account by Warren $(1972,1974)$ of color-naming interference. For example, Burt (1994) observed a small facilitatory effect of word frequency in the noncolor word Stroop task, with high-frequency words having faster responses than low-frequency words. The rare words were less rare than those employed by Klein (1964), and words were not repeated. Possibly, Klein's subjects ignored his very low-frequency words, thus showing interference for high- relative to low-frequency words. In the same paper, Burt found facilitation of color naming when primes were identical to targets (but see McClain, 1983). Facilitation of color naming also has been reported in sentencepriming studies in which subjects covertly generated the target word upon sentence presentation (Dosher \& Corbett, 1982; Whitney, 1986). In the literature on processing biases in anxiety disorders and phobias, facilitation of color naming has been observed, a result that contrasts with the typical result of retardation of color naming to threat words (Mathews \& C. MacLeod, 1985; Mogg, Mathews, \& Weinman, 1989; Watts, McKenna, Sharrock, $\&$ Trezise, 1986). For example, students under high-state anxiety because of impending examinations named the colors of (unmasked) examination-related threat words more quickly than they named the colors of control words (C. MacLeod \& Rutherford, 1992).

The above findings imply that facilitation of target word processing sometimes can facilitate, rather than interfere with, color naming. ${ }^{1}$ It is proposed here that the mixed pattern of interference and facilitation observed in the noncolor word Stroop task can be illuminated by a closer examination of the attentional demands of the task. Additional concerns about the utility of Warren's version of a horse race account are raised by recent work challenging the viability of such models as accounts of interference in the standard color word Stroop (see the review by C. M. MacLeod, 1991). On the present approach, the attentional demands of the color-naming task are viewed in terms of recent models (e.g., Meyer \& Kieras, 1997) in which limitations on dual-task performance can be understood as reflecting general processing capacity limitations and structural bottlenecks.

A general processing capacity limitation arises during encoding of the base word and the color name. Evidence that encoding of a visually presented word demands processing resources comes from studies employing dual-task paradigms (Becker, 1979; Herdman, 1992). In the standard procedure for the Stroop test with color names or noncolor words, the base word is printed in colored lettering; as a consequence, the color name and the base word cannot readily be separated spatially. Therefore, the at- tentional demands of base-word reading may be assumed to underlie the small interference in color naming that is observed when the lettering color of a noncolor word is named, as compared with a baseline condition in which subjects name the color of a string of Xs or asterisks (e.g., Klein, 1964; Warren, 1972).

A structural source of color-naming interference may arise when the color name and the base word both become available for output, as was suggested by Warren (1972). The magnitude of interference arising at the stage of response preparation and output is likely to be smaller in the noncolor word task than in the standard, color word Stroop task. In the latter task, the activation of two conceptually similar responses (color names) provides a source of response conflict that is not present in the noncolor word task. Also, in the color word task, the naming of colors on preceding trials may provide opportunities for activating the competing response (Neill, 1978). The present proposal about structural interference at output in the noncolor word task differs from Warren's (1972) in that the extent of structural interference associated with activation of two vocal responses is not determined primarily by the relative rate of activation of the responses for the base word and the color name. Rather, it is the level of activation of the base-word response that is the major determinant of interference.

The degree to which the base word becomes available as a competing response may depend on the level of its phonological activation during preparation of the colornaming response. There is evidence that the degree of activation or utilization of a word's phonological representation during word recognition tasks may be influenced by task factors (Davelaar, Coltheart, Besner, \& Jonasson, 1978; Jared, McRae, \& Seidenberg, 1990; Parkin, 1983; Van Voorhis \& Dark, 1995). Plausibly, for unprimed words during the noncolor word Stroop task, subjects read the base word, but there is only weak activation from the word's phonological representation to the vocal output level of the processing system, and the very small amount of color-naming interference observed with noncolor base words reflects the processing demands of word recognition. When stimulus presentation and wordprocessing instructions increase the salience of lexical, semantic, or phonological properties of the base word, and a vocal color-naming response is required, the phonological activation of the base word is likely to be increased, with a consequent increase in the probability of a response bottleneck.

In the associative priming paradigm in the noncolor word Stroop task, it is proposed that there is an increase in the competition for output between related target words and the color name, as the outcome of a shift of attention from the primary color-naming task to meaningbased processing of the stimuli of the secondary, wordreading task. This diversion of attention to processing related targets (and primes) is assumed to be driven by characteristics of the stimulus materials and by the temporal parameters of stimulus presentation. Specifically, 
it is proposed that the salience of the relatedness of primes and targets promotes target- or prime-processing that has to do with the prime-target association. This processing may occur if conditions such as response requirements make it difficult for subjects to ignore the relatedness of primes and targets. Otherwise, because diversion of attentional resources to processing the base word may impede the primary task of color naming, subjects are expected to ignore the nature of the primes and targets as far as possible.

Experiments 1 and 2 assessed whether color-naming interference from associative primes in the noncolor word Stroop task depends on two conditions that are expected to induce subjects to focus on the prime-target relation. These conditions are a prime response that requires reading of the prime and meaning-based processing of the prime and a salient prime-target relationship.

In the absence of factors distracting subjects from the primary task of color naming, facilitating word recognition normally can be expected to facilitate color naming in the noncolor word task. The reason is that the magnitude or the duration of the concurrent processing load associated with the word-reading and color-naming task is reduced. As was noted above, there is evidence for a latency advantage for high-frequency words and words preceded by visually presented identity primes in color naming (Burt, 1994). The advantage in processing time of high-over low-frequency words is ubiquitous and fundamental to theories of word recognition (e.g., Forster, 1976; Morton, 1969). Therefore, word frequency provided a useful marker variable in Experiment 1 for the effects of speeded word reading on color naming. Experiment 3 pursued the possibility that, under appropriate conditions, associative primes may facilitate color naming by virtue of facilitating base-word recognition.

\section{EXPERIMENT 1}

Previous research on associative priming in color naming has shown the importance of the prime response requirement in producing associative interference. The requirement that the prime be recalled after color naming has yielded interference by associative primes (Burt, 1994; Warren, 1972), as has an overt pleasantness or animate/ inanimate judgment about the prime (Parkin, 1979) and naming of the prime (Henik et al., 1983), whereas silent reading of the prime (Burt, 1994) and overt responses based on counting the prime's syllables (Parkin, 1979) and searching for a letter in it (Henik et al., 1983) have not produced interference. From these findings, it is inferred that color-naming interference by associative primes is likely only if subjects recognize the prime and make a response involving the processing of lexical properties or meaning of the prime.

Experiment 1 was designed to provide support for the above inference in groups either reading the prime silently or reading the prime and making a lexically based judgment about it. The prime task for the latter group was lex- ical decision, which has an advantage over the prime recall task used by Warren (1974) and Burt (1994) in that the prime response is made before target presentation and, thus, the prime task is less likely to exert a direct disruptive effect on processing of the target and color.

The prime-target association was made salient by means of a stimulus list having a large proportion of strongly related prime-target pairs. Under these conditions, it is expected that subjects making a lexical decision to the prime will be unable to ignore the prime-target association. As a consequence, they may engage in processing of the target or the prime that results in activation of the target, which leads to competition for output between the target word and the color name. It is possible that the prime word also participates in competition for output. Subjects only reading the prime may be more able to ignore semantic relationships among the words.

A second purpose of the first experiment was to provide an assessment of target frequency effects in the noncolor word Stroop task. Given that the target frequency effect is manifest as a direct relation between color-naming latencies and inferred word-reading speed (shorter latencies for high-than for low-frequency words), whereas the typical associative priming effect involves an inverse relation between color-naming latencies and inferred target-reading speed (longer latencies for primed than for unprimed words), it was of interest to discover whether these contrasting effects on latencies could be demonstrated within a single experiment.

\section{Method}

Subjects. Sixty-five introductory psychology students, all native speakers of English without marked defects in color vision, were assigned at random to the condition requiring lexical decisions to the prime ( $\mathrm{LD}, n=32$ ) or the condition requiring silent reading of the prime (read, $n=33$ ). Data from one read subject were discarded because of excess microphone failures. The subjects received course credit for their participation.

Materials and Design. Forty-six pairs of associates of moderate to high strength were taken from the norms of Nelson, McEvoy, and Schreiber (1992) and a further pair was taken from each of Palermo and Jenkins (1964) and Thomson, Meredith, and Browning (1976), to make a total of 48 pairs. Twenty-four pairs had response terms (targets) of high frequency (mean, 445; range, 118-2,724; Kučera \& Francis, 1967), and the remaining 24 pairs had targets of low frequency (mean, 7; range, 0-15; Kučera \& Francis, 1967). The targets in the high- and low-frequency sets were 3 to 6 letters long and were matched on length distribution (mean, 4.46; median, 4 letters). The normative associative strength of prime-target pairs in the high and low sets was also matched (mean strength of $50 \%$ and $51 \%$ for high- and low-frequency sets, respectively; range, $29 \%-88 \%$, defined as the percentage of subjects giving the target as their first associative response to the prime)

An additional set of 48 single words, matched on length to the associative targets, was selected as targets for nonword primes. They had a mean frequency in the Kučera and Francis (1967) corpus of 40 (range, 10-98). For the nonword primes, 48 orthographically legal nonsense strings were devised to match the length of the associative primes (mean of 4.85 letters)

For the purposes of counterbalancing, the high- and lowfrequency pairs were divided into two subsets of 12 pairs that were approximately matched on mean target length. For the first coun- 
Table 1

Experiment 1: Mean Color-Naming Latencies (in Milliseconds) and Error Percentages for the Two Prime Processing Groups as a Function of Target Frequency and Prime-Target Relatedness

\begin{tabular}{|c|c|c|c|c|}
\hline \multirow[b]{3}{*}{ Relatedness } & \multicolumn{4}{|c|}{ Target frequency } \\
\hline & \multicolumn{2}{|c|}{ High } & \multicolumn{2}{|c|}{ Low } \\
\hline & RT & PE & RT & $\mathrm{PE}$ \\
\hline \multicolumn{5}{|c|}{ Read Group } \\
\hline Related & 542 & 0.78 & 556 & 0.78 \\
\hline Unrelated & 545 & 1.30 & 552 & 0.78 \\
\hline \multicolumn{5}{|c|}{ LD Group } \\
\hline Related & 588 & 1.30 & 620 & 1.56 \\
\hline Unrelated & 572 & 1.56 & 589 & 1.82 \\
\hline
\end{tabular}

terbalanced list, the first subset of each frequency was presented intact, and the remaining two subsets had primes and targets randomly repaired to make unrelated pairs. For the second list, the converse allocation of subsets to related and unrelated conditions was made. The two subgroups receiving each of these lists representing the assignment of items to prime type were treated as levels of a counterbalancing factor in the latency analyses. The two lists were combined with the nonword prime pairs, and four versions of each list were prepared by rotating the targets through the four colors, so that over the final eight sets, each target appeared once in each color in a related and an unrelated pair. Within each set, each color-condition combination was equally represented. The pairs in each set were randomly sequenced, with the constraint that a color did not occur on more than three consecutive trials. Four subjects in each group were tested on each set.

Procedure. The subjects wore a boom microphone and were tested individually on a BBC microcomputer with an Amust color monitor and a button box. The microphone was connected via a voice-operated relay to a microswitch on the computer. On each trial, the prime was displayed in white, double-height, uppercase letters in the center of the screen for $700 \mathrm{msec}$ (read condition) or until a buttonpress was made (LD condition). The screen remained blank for $500 \mathrm{msec}$ before the target was presented in doubleheight, lowercase letters in the center of the screen, in red, blue, green, or purple (BBC magenta). After the subject's vocal response to the target, the experimenter pressed a key to indicate whether the response was correct, incorrect, or correct but the microphone had failed. The keypress cleared the screen and initiated an intertrial interval of $3,500 \mathrm{msec}$.

The subjects were informed about the four colors used for target words and were asked to name the color of the lettering as quickly as possible, without making too many (more than 1 in 20) errors. They were told that a white uppercase letter string would appear shortly before each colored word and that they should read the white letter string silently (read condition) or press the right or the left button on the response box to indicate whether the letter string was a word or a nonword (LD condition). The subjects in the LD group were asked to rest the index finger of their right and left hands on the right and left buttons and to make their lexical decision responses as quickly and accurately as possible. The preferred hand was used for word responses. A practice block of 20 unrelated primes and targets preceded the test session.

\section{Results}

The subjects in Group LD made word and nonword decisions to the primes in a mean of 599 and $726 \mathrm{msec}$, respectively, with the error rate for words being $2.9 \%$ and for nonwords $8.6 \%$. The exclusion of trials with an incorrect lexical decision to the prime did not affect statistical inferences and produced variation in the mean latencies for each condition of less than 2 msec. The analyses reported below are those for which color-naming latencies for trials with an error in the lexical decision to the prime were retained.

The mean color-naming latencies for the high- and low-frequency targets in the related and unrelated prime conditions are shown, with the mean error percentages, in Table 1. The data for the filler words paired with nonword primes were not analyzed. In this and subsequent experiments, analyses of variance (ANOVAs) were conducted on the data of interest by both subjects $\left(F_{1}\right)$ and items $\left(F_{2}\right)$, with an alpha value of .05 .

A prime-processing group $\times$ target frequency (high vs. low) $\times$ prime type (related vs. unrelated) ANOVA of color-naming error percentages revealed no significant effects of group, frequency, prime type, or their interaction [for groups, $F_{1}(1,62)=1.55, M S_{\mathrm{e}}=11.2, F_{2}(1,46)=1.88$, $M S_{\mathrm{e}}=1.7, p>.05$; all other $F_{1} \mathrm{~s}$ and $\left.F_{2} \mathrm{~s}<1\right]$.

Prior to analysis of mean color-naming latencies, trials with microphone failures, errors, and, within prime type condition, latencies of more than three standard deviations above or below a subject's correct mean latency were removed. In the LD data, microphone failures and extreme latencies accounted for $1.4 \%$ and $2.2 \%$ of trials, respectively, with the corresponding rates for the read data being $1.2 \%$ and $1.9 \%$ of trials, respectively. A prime-processing group $\times$ counterbalance set (one vs. two) $\times$ target frequency (high vs. low) $\times$ prime type (related vs. unrelated) ANOVA of the mean latencies confirmed that latencies were longer in the LD than in the read group $\left[F_{1}(1,60)=\right.$ $\left.7.73, M S_{\mathrm{e}}=15,613 ; F_{2}(1,44)=78.72, M S_{\mathrm{e}}=1,144\right]$. The main effect of target frequency was significant, with faster responses to high frequency $\left[F_{1}(1,60)=12.86, M S_{\mathrm{e}}=\right.$ 1,$\left.480 ; F_{2}(1,44)=7.13, M S_{\mathrm{e}}=2,181\right]$. The interaction of group and prime type also was significant $\left[F_{1}(1,60)=7.34\right.$, $\left.M S_{\mathrm{e}}=1,183 ; F_{2}(1,44)=4.23, M S_{\mathrm{e}}=1,461\right]$. A simple main effects analysis confirmed that there was priming interference within Group LD $\left[F_{1}(1,30)=10.89 ; F_{2}(1,44)=\right.$ $4.48]$ but not within the read group $\left(F_{1}\right.$ and $\left.F_{2}<1\right)$. No other effect was reliable or nearly so, in both subjects and items analyses.

\section{Discussion}

The lexical decision group showed color-naming interference for related targets, replicating the initial findings in the noncolor word Stroop task (Warren, 1972, 1974). This group was slower than the read group (by $32 \mathrm{msec}$ on unrelated trials), presumably reflecting the effect of the prime task on preparation for responding to the target. Of most interest was the significant primeprocessing group $\times$ prime type interaction, reflecting priming interference in color naming in the LD but not the read group. This finding, together with previous examinations of prime processing in the noncolor word Stroop task (Burt, 1994; Henik et al., 1983; Parkin, 1979), supports the prediction that color-naming interference by associative primes depends on the nature of the prime task. Minimally, if related primes are to interfere, subjects must read the prime and engage in further processing on 
the basis of recognition of the prime word. Because all previous studies demonstrating associative interference in color naming have had the additional requirement of an overt response to the prime, in some or all cases this factor may be crucial to interference. For example, an instruction to name the prime compels subjects to engage in additional processing beyond prime recognition. For pleasantness judgments, lexical decision, and prime recall, an overt response requirement ensures that subjects comply with prime-processing instructions. Finally, the prime response may exert an additional effect on prime and target processing through its own processing demands.

The failure of the subjects in the read group to show any priming effect mirrors previous findings for silent reading of the prime in the noncolor word Stroop task (Burt, 1994). In contrast, it is well established that, at primetarget stimulus onset asynchronies (SOAs) similar to that of Experiment 1, priming facilitation occurs in lexical decision (den Heyer, 1985; L.C. Smith, Briand, Klein, \& den Heyer, 1987) and naming tasks (Keefe \& Neely, 1990; Lorch, Balota, \& Stamm, 1986) when the prime response is silent reading. Thus, this finding for the read group points to an important difference between the noncolor word Stroop task and other word recognition tasks. In the color-naming task, the prime is not relevant to, and may disrupt, the color-naming response. Therefore, it is likely that subjects comply with instructions to read the prime by restricting their prime processing to word recognition, without any additional meaning-based or lexical-level processing.

Overall, target frequency had a significant effect on response latencies. As in previous work (Burt, 1994), the frequency effect was manifest as faster color naming for high- than for low-frequency targets. The occurrence of a frequency facilitation and a priming interference effect within the study supports the present view that the two effects differ in their mechanisms. Nevertheless, there are alternative explanations of associative priming interference in color naming that are not ruled out by the present results. For example, it has been suggested that deeper processing activates a greater number of semantic features of the prime than does shallow processing (M. C. Smith, Theodor, \& Franklin, 1983), so that the results for the read group may reflect weaker associative priming. Also, it is arguable that (contrary to their reports) the subjects in the read group were not reading primes at all.

Experiment 2 was designed to present converging evidence in support of the present account of color-naming interference from associative primes. Specifically, it assessed the role in interference of subjects' awareness of the relatedness of primes and targets. No color-naming interference was predicted when the salience of the prime-target relation was low.

\section{EXPERIMENT 2}

In the prototypical study of semantic priming, the prime precedes the target by $2 \mathrm{sec}$ or less, and the response to the target is followed by a delay of several seconds or more. The effect of this temporal arrangement of stimuli is to group the prime and the target as a pair of items and to enhance the relevance of the prime in responding to the target. Priming effects have been observed in lexical decision when this grouping is destroyed by presenting the prime and the target at equal intervals (Fischler, 1977; McNamara \& Altarriba, 1988). However, recent studies by Shelton and Martin (1992) have provided evidence that the priming observed under this single-presentation arrangement does not depend on factors requiring subjects' awareness of the prime-target relationship.

In Experiment 2, associative priming was examined in subjects who had either the temporally paired or the single-presentation format. On the basis of the hypothesis that priming interference in the noncolor word Stroop task is the result of response conflict arising from an increased priority given to the processing of related targets, it was predicted that single-word presentation would abolish the interference. Given that the magnitude of priming in naming and lexical decision is known to vary with the primetarget SOA (e.g., Neely, 1991, pp. 275-277), confounding of SOA and presentation was avoided by holding SOA constant over groups and varying the intertrial interval. The subjects were asked to name the prime word aloud, a response requirement that supported colornaming interference in the study by Henik et al. (1983).

\section{Method}

Subjects. Sixty-seven introductory students, all native English speakers, participated for course credit. The data of 3 subjects were discarded, either because of excessive microphone failures (1 subject) or because of absent or inappropriate responses to primes or targets ( 2 subjects). Data were provided by 32 subjects in each of the paired and even presentation conditions.

Materials. Sixty-four associated prime-target pairs of moderate to high association strength were taken from word association norms (Palermo \& Jenkins, 1964; Postman, 1970; Thomson et al., 1976). The targets were 4 to 8 letters long (mean, 4.82) and had a mean frequency of 169 (Kučera \& Francis, 1967; range, 3-2,724; median, 62). The primes were 3 to 7 letters long (mean, 5.0) and had a mean frequency of 84 . An additional 16 words from the Kučera and Francis corpus served as targets for neutral prime trials (mean length $=4.82$ letters, median frequency $=59$ ). These words were not included in the counterbalancing of prime type and, consequently, could not be included in item analyses of priming effects. Their purpose was to provide information on the adequacy of the unrelated prime condition as a baseline for the assessment of priming effects.

For the purposes of counterbalancing, the prime-target pairs were divided into two equal subsets matched on mean target length. In one counterbalanced set, the items in the first subset remained paired, and the items in the second subset were randomly re-paired to produce unrelated pairs. The second set had the converse allocation of items to conditions. The targets in each set were combined with the 16 neutral trial targets, which had the prime NEXT, and were rotated through the four colors, as was described previously, to produce eight sets of 80 pairs each. The sequence of trials was randomized, except that a color did not appear more than three times in succession, as was described previously. Four subjects per group were allocated to each stimulus set.

Procedure. The apparatus was the same as that described in Experiment 1 . Primes were presented in white uppercase letters, and targets in colored lowercase letters. 
Table 2

Experiment 2: Mean Color-Naming Latencies (in Milliseconds) and Error Percentages for the Two Presentation Groups as a Function of Prime-Target Relatedness

\begin{tabular}{llllll} 
& \multicolumn{2}{c}{ Paired Presentation } & & \multicolumn{2}{c}{ Single Presentation } \\
\cline { 2 - 3 } \cline { 5 - 6 } Relatedness & RT & PE & & RT & PE \\
\hline Related & 732 & 2.6 & 661 & 4.0 \\
Unrelated & 706 & 2.5 & 658 & 3.4 \\
\hline
\end{tabular}

The subjects were instructed to read the prime words aloud "in their own time" (including the neutral prime NEXT) and, as was described in Experiment 1, to name the color of the target words as quickly and accurately as possible. In the paired condition, the target was presented $3 \mathrm{sec}$ after the onset of the prime, and the prime presentation for the next trial began $5.5 \mathrm{sec}$ after the onset of the target. In the single condition, there was an interval of $3 \mathrm{sec}$ from the onset of one word to the onset of the next. After the subjects named the target color, the experimenter pressed a key to indicate whether the response was correct, incorrect, or invalid, as was described for Experiment 1. The keypress cleared the word from the screen. If the subject's response and the experimenter's keypress took longer than the predetermined interword interval, the next word was presented $100 \mathrm{msec}$ after the experimenter's keypress. Prior to completing the test block, the subjects practiced on 35 prime-target pairs, 28 with unrelated and 7 with neutral primes.

\section{Results}

Prior to analysis, latencies for incorrect target responses, trials with microphone failures, and, within related versus unrelated plus neutral prime type, latencies in excess of three standard deviations from a subject's correct mean were excluded. There was a loss of $0.6 \%$ (microphone failures) and $3.9 \%$ (extreme latencies) of trials in the paired group and of $0.2 \%$ (microphone failures) and $4.8 \%$ (extreme latencies) of trials in the single-presentation group, in addition to the trials lost to errors on targets. There were 12 trials in the data of the single-presentation group for which the target was displayed for more than $3 \mathrm{sec}$ after the onset of the prime, mainly because of microphone failure for the prime response. Most of the responses to these delayed targets had latencies exceeding the subject's average latency. Because exclusion of the trials that survived preprocessing did not affect the analyses, these trials were retained.

The mean color-naming latencies for target words in the two presentation conditions are shown, with error percentages, in Table 2. Mean latencies on neutral trials were $715 \mathrm{msec}$ (paired group) and $658 \mathrm{msec}$ (single group). A presentation group (paired vs. single) $\times$ prime type (related vs. unrelated) ANOVA of error percentages showed that the effects of prime type and the group $\times$ prime type interaction were not significant $\left(F_{1}\right.$ and $\left.F_{2}<1\right)$, and the tendency for the single group to have a higher error rate was reliable only in the items analysis $\left[F_{1}(1,62)=2.6\right.$, $\left.M S_{\mathrm{e}}=15.5, p=.11 ; F_{2}(1,63)=4.9, M S_{\mathrm{e}}=4.5\right]$.

A group $\times$ counterbalance set (one vs. two) $\times$ prime type ANOVA of mean latencies revealed a significant effect of group, with slower responses in the paired group $\left[F_{1}(1,60)=9.29, M S_{\mathrm{e}}=12,342 ; F_{2}(1,62)=177.91\right.$, $\left.M S_{\mathrm{e}}=1,253\right]$, and a main effect of prime type, reflecting interference from related primes $\left[F_{1}(1,60)=12.07, M S_{\mathrm{e}}=\right.$ $\left.539 ; F_{2}(1,62)=10.31, M S_{\mathrm{e}}=1,460\right]$. The group $\times$ prime type interaction was significant in the subjects analysis and marginal in the items analysis $\left[F_{1}(1,60)=7.05, M S_{\mathrm{e}}=\right.$ $\left.539 ; F_{2}(1,62)=3.78, M S_{\mathrm{e}}=1,932, p=.06\right]$. There was no significant effect involving counterbalance set. Planned comparisons of related and unrelated prime conditions were conducted for each group separately, at $p=.025$ (Bonferroni adjustment; Hays, 1981). There was no reliable interference in the single group $\left(F_{1}\right.$ and $\left.F_{2}<1\right)$. The interference effect of $26 \mathrm{msec}$ in the paired group was reliable $\left[F_{1}(1,30)=13.71 ; F_{2}(1,62)=6.18\right]$. A planned comparison of latencies on neutral $(716 \mathrm{msec})$ and unrelated trials within the paired group was not significant $\left[F_{1}(1,30)=1.3, p>05 ; F_{2}<1\right]$.

\section{Discussion}

The single-presentation condition, requiring as it does that subjects alternate quickly and regularly between word naming and color naming, resulted in a 48-msec latency advantage on unrelated trials for the single group, relative to the paired group. This faster response time was achieved at the cost of a slightly higher error rate, over all conditions, in the single than in the paired group, a difference that was not reliable in the subjects analysis. Some errors in the data for this group involved naming the target word instead of its color. Of the 21 subjects in the single-presentation condition who made errors, only 8 made more errors on related than on unrelated trials. Consequently, there is no evidence of a priming effect in the error data for this group. Also, because latencies were not markedly more variable in the single-presentation than in the paired condition, the failure of the singlepresentation group to show a priming effect cannot be attributed to undue noise in the data.

The results of Experiment 2 support the prediction that priming interference depends on the salience of the prime-target relationship. When the prime and target were temporally paired, priming interference was observed; when the temporal pairing of primes and targets was removed for the single-presentation condition, no priming interference was observed. Therefore, the results of Experiments 1 and 2 are amenable to a single explanation: When conditions promote awareness of the prime-target association, subjects may engage in processing of related target words or primes that leads to conflict between colorname and word responses.

Experience at the single-presentation task and the subjects' reports indicated that the manipulation did decrease the salience of the prime-target relationship. It is arguable that this reduction in salience did not result from the temporal distribution of primes and targets, but rather resulted from the subjects' focusing on their response alternations. Because the subjects responded more quickly in the single than in the paired condition, it is unlikely that the regular response alternations in the single condition were unduly demanding. In any case, this possibility is compatible with the present view, in that drawing the 
subjects' attention away from the prime-target association is expected to eliminate priming interference.

\section{EXPERIMENT 3}

Experiments 1 and 2 were based on the premise that priming interference arises when subjects direct their attention to the target or prime, with a consequent activation of responses that compete at output with the color name. Manipulations designed to reduce attention to the prime and the prime-target relationship attenuated color-naming interference.

In many cases, associative priming in word recognition tasks does not appear to depend on subjects' awareness of the prime-target relation (see, e.g., Marcel, 1983). In addition, priming may occur when it appears to be unlikely that subjects are engaging in strategies that may facilitate responses to related targets-for example, the generation of expectancies about the target or retrospective processing of the prime and the target (Fischler, 1977; Shelton \& Martin, 1992). Nonstrategic effects are evident at short prime-target SOAs, whereas expectancy and other prospective strategies require approximately $500 \mathrm{msec}$ to be deployed (Neely, 1991). The temporal persistence of nonstrategic priming is not known, but it is commonly assumed that, for unmasked primes, such effects dissipate within approximately $2 \mathrm{sec}$ (Neely, 1977).

In Experiments 1 and 2, the prime-target SOAs were longer than is optimal for nonstrategic priming (approximately 1,200 and $3,000 \mathrm{msec}$, respectively), and inattention to the prime, strategic priming effects, and other sources of variability in the color-naming task may have masked any nonstrategic priming effects. A short SOA with no prime response requirement is the optimal condition for demonstrating purely nonstrategic priming effect in color naming, given that there will be a weaker involvement of expectancy strategies. The minimal requirement for priming, that subjects read the primes, is likely to be met, because subjects are looking at the prime location in anticipation of the imminent presentation of the target.

The question pursued in Experiment 3 is whether, in conditions not promoting competition at output between the target or the prime word and the color name, priming will be evident as facilitation or interference in color naming. The present view (see Burt, 1994) is that, in contrast to Warren's $(1972,1974)$ horse race model, nonstrategic facilitation of target word recognition in the noncolor word Stroop task may speed color naming. Analogously, faster processing of high- than of low-frequency targets (Experiment 1 ) and for targets preceded by identical rather than by unrelated primes (Burt, 1994) was manifested as shorter color-naming latencies for the more quickly processed targets. A demonstration of priming facilitation in color naming would provide more direct support for the claim that interference observed in associative priming reflects response conflict in color naming rather than a facilitation of target word recognition. Thus, in Experiment 3 , associative priming was examined with un- masked primes at a short (120-msec) prime-target SOA, and it was predicted that color naming would be faster after related than after unrelated primes. Items were counterbalanced in two blocks, so that the development of priming effects during the session could be assessed.

\section{Method}

Subjects. Thirty-two introductory psychology students who were native speakers of English participated for course credit.

Materials. Eighty associate pairs of moderate to high associate strength were taken from association norms (Palermo \& Jenkins, 1964; Postman, 1970; Thomson et al., 1976). The associative targets had mean and median frequencies of 146 and 64 , respectively (Kučera \& Francis, 1967), and were 4 to 8 letters long (mean, 4.81). An additional 16 single words, taken from the same sources and comparable in frequency and length with the associative targets, served as targets on neutral prime trials for which the prime was the word NEXT

The 80 related pairs were divided into four subsets of 20 pairs approximately matched on target length and frequency. The four subsets were combined into two blocks (A and B) of two subsets each, with one subset in each block intact and the primes in the other subset randomly repaired to make unrelated trials. A second version of each block was created by reversing the allocation of subsets to conditions. Block A preceded Block B to make up two counterbalanced lists of 80 pairs. Eight of the 16 baseline pairs were added to each block, and the targets were cycled through the four colors, as was described previously, to make eight sets counterbalanced for condition and target color. Trials were presented in a random sequence, with no more than three successive occurrences of a color and with a set of 4 practice pairs ( 2 related, 2 unrelated) placed at the beginning of the first block. Three subjects were assigned to each stimulus set.

Procedure. The subjects were tested individually, as was described previously. The prime word was presented in doubleheight, lowercase white letters for $50 \mathrm{msec}$, the screen was cleared, and $70 \mathrm{msec}$ later the target was presented in double-height, colored lowercase letters. The subjects gave their color-naming responses, and the experimenter scored them as was described in Experiments 1 and 2. After the target was removed from the screen, there was a 4-sec interval before the next trial. Sixteen unrelated trials were given as practice before the two test blocks were run without interruption.

\section{Results}

Errors were infrequent (range, $0.9 \%-1.5 \%$ ) and did not differ for unrelated and related trials $\left(F_{1}\right.$ and $\left.F_{2}<1\right)$. Latency data were preprocessed, as was described previously, with $1.4 \%$ of the trials being lost through microphone failures and $2.3 \%$ of the trials as extreme times. The mean latency for the related trials was $557 \mathrm{msec}$; the mean latency for the unrelated trials was $567 \mathrm{msec}$; and the mean latency for the neutral trials was $574 \mathrm{msec}$.

A counterbalance set (one vs. two) $\times$ prime type (related vs. unrelated) ANOVA of mean color-naming latencies showed a significant facilitation for related over unrelated trials $\left[F_{1}(1,30)=6.48, M S_{\mathrm{e}}=208 ; F_{2}(1,78)=\right.$ $\left.4.70, M S_{\mathrm{e}}=617\right]$. A planned comparison for the unrelated and neutral latencies was not significant $\left(F_{1}\right.$ and $\left.F_{2}<1\right)$. Breakdown of the latency data into the counterbalanced session halves showed no main or interactive effect of session half $\left(F_{1}\right.$ and $\left.F_{2}<1\right)$, with the mean unrelated minus related latency being 7 and $12 \mathrm{msec}$ over the first and second halves, respectively. 


\section{Discussion}

The predicted facilitation for priming by an associate of each target was small but reliable in the analysis of mean latencies. The successful demonstration of priming facilitation in color naming adds to a substantial literature on facilitation in response accuracy or latency by semantically related primes in word naming, lexical decision, and perceptual identification. As such, it adds weight to the common supposition that, at relatively short prime target SOAs, target recognition may benefit nonstrategically from prime word reading.

Because primes and targets were associated on $42 \%$ of the trials, it is likely that the subjects became aware of the prime-target relationship. The short prime-target SOA precluded the generation of expectancies about the target from the prime, but not retrospective processing of the prime-target association. Retrospective processing may not occur if there has been minimal associative processing of the prime prior to the presentation of the target. Under these conditions, subjects may have little difficulty ignoring the prime-target association while they prepare the color-name response.

\section{GENERAL DISCUSSION}

Experiments 1 and 2 confirm previous studies of associative priming in color naming, and taken together, the studies are consistent with a body of evidence indicating that related primes retard target color naming only when certain conditions are met - namely, the task requires subjects to make a lexically based response to the prime, and the prime-target relationship is salient. No significant interference has been observed when subjects silently read the prime (Burt, 1994, Experiment 1) or conducted a letter search (Henik et al., 1983) or syllable judgment (Parkin, 1979 ) on the prime. In all cases of interference by singleword primes (Henik et al., 1983; Parkin, 1979; Warren, 1972, 1974), the prime-target relationship was obvious, in that primes and targets were paired and the proportion of related pairs was at least $30 \%$. Similarly, in studies showing interference by sentence primes (Conrad, 1974; Merrill et al., 1981; Oden \& Spira, 1983; Whitney, 1986; Whitney et al., 1985), the relatedness of sentence primes and targets was salient.

In Experiment 2, the prime task was naming, which was adequate to produce priming in a study by Henik et al. (1983), but priming was observed only when the primetarget relationship was made salient by temporal pairing of primes and targets. At the long prime-target SOAs used in Experiments 1 and 2, it is assumed that the salience of the prime-target association fosters the development of expectancies about the target word that affect the manner in which subjects process the target or the prime words. In addition, it is possible that retrospective strategies are deployed, such as recalling a related prime to engage in further analysis of the prime-target relationship. These strategies may not be detrimental to performance in lexical decision and naming tasks. However, in the color- naming task, it is proposed that such strategies increase competition for output between activated target or prime words and color names.

The results of Experiment 3 indicate that when factors promoting attention to the target are minimized, any effect of associative primes is manifested as a small facilitation of color naming. This facilitation is taken here to be an index of speeded word processing, and a similar inference is drawn about the facilitation for high- over lowfrequency words (Burt, 1994, Experiments 1 and 4; Burt, 1999 ) and the facilitatory effects of visually presented identity primes on color naming (Burt, 1994). The underlying assumption is that word reading and color processing are conducted in a parallel or cascaded fashion, so that faster word reading results in faster color naming. The basis for speeded color naming is considered further in a later section.

\section{Horse Race Models of \\ Facilitation and Interference}

A horse race model of the priming and frequency effects observed in the noncolor word Stroop task is not viable, because such a model cannot incorporate both priming interference and facilitation, or both priming interference and frequency facilitation effects. For example, in Experiment 1, Group LD displayed a target frequency effect, with shorter latencies for high-frequency targets, and a priming interference effect, with longer latencies for related targets. A potential account of frequency and priming effects might start from the assumption that priming causes the mean processing completion times for high-frequency words to fall after the preparation of the color-naming response (unrelated prime) and just before this response preparation (related prime). Alternatively, it might be assumed that the mean processing completion times for low-frequency targets fall just before (related prime) and after (unrelated prime) the preparation of the color-naming response. In either case, priming effects would be predicted to interact with target frequency in such a way that priming was observed only at one level of frequency. This prediction is not supported in Experiment 1 or in the previous study by Burt (1994).

An alternative possibility is that facilitatory effects of primes and frequency effects may be explained in terms of the relative speed of the color and word pathways, with priming interference explained by a separate mechanism (cf. Burt, 1994). This adaptation of the horse race model allows a viable account of the present facilitation results, although it is based on rejection of the original account given by Warren $(1972,1974)$ of priming interference effects. The present view is that rapid word processing is conducive to rapid color naming only in those situations in which the level of activation of the base word for output is low. Thus, as will be discussed below, word-processing speed plays a role in terms of the concurrent processing load for the word and color dimensions, rather than in terms of the timing of the availability of the word and color-name responses. 


\section{Basis of the Color-Naming Interference}

Recent models of the standard color word Stroop task may have some application to the interference observed here and previously when subjects make lexically based responses to related primes at longer prime-target SOAs (Burt, 1994; Henik et al., 1983; Parkin, 1979; Warren, $1972,1974)$. One set of models that account for phenomena reported in the color word Stroop task was devised by Cohen and colleagues (Cohen, Dunbar, \& McClelland, 1990; Cohen \& Huston, 1994; Cohen, Schreiber, \& McClelland, 1992). In these models, there are two processing pathways for the colors and the words, terminating in a set of color-name response units. The basis of interference is differential activation in the color and word pathways, rather than differences in processing speed. In the context of associative priming with noncolor words, it is proposed here that the allocation of resources to the processing of the prime-target association on related trials increases the activation in a pathway from lexical units for the prime or the target to corresponding output units. This increased activation results in competition for output between the base word (or perhaps the prime) and the color name.

The present results provide no direct evidence concerning the nature of the base-word and color-name activation that leads to competition for output. It is proposed that meaning-based processing of the base word increases its phonological activation, with activation flowing to its articulatory program. In line with the proposal by Warren $(1972,1974)$, the articulatory program for the base word competes for output with the articulatory program for the color name. According to this proposal, manipulations that increase the activation of the target phonology will produce color-naming interference. Consistent with this expectation, visual identity primes may produce interference when a phonological (rhyme judgment) response is made to the prime or when the prime is presented auditorily and the prime task requires subjects to attend fully to the prime (Burt, 1999).

A response conflict model of increases in color-naming interference in the noncolor word Stroop task is favored here because of its potential to provide a parsimonious explanation of the above findings with phonological processing of primes, together with previously reviewed findings of color-naming interference in conditions involving meaning activation of the base word and of colornaming interference from threat-related base words (Mathews \& C. MacLeod, 1985; Mogg et al., 1989; Watts et al., 1986). It has the additional virtue of broad compatibility with current successful accounts of interference in the standard color word task (C. M. MacLeod, 1991). Future research may clarify whether the associative priming interference effect is best understood in terms of response competition. An alternative possibility is that interference results from a reduction in the resources available for preparation of the color-name response.

\section{Color-Naming Facilitation}

Faster responding to targets preceded by associative or identity primes and faster responding to high- than to low-frequency words are well-documented effects in word recognition tasks. Included are lexical decision (see Forster \& Davis, 1984; Monsell, 1991; Neely, 1991), pronunciation (Andrews, 1989; Burt, 1994; de Groot, 1985; Forster \& Chambers, 1973), and perceptual identification (Burt, Walker, Humphreys, \& Tehan, 1993; Humphreys, Besner, \& Quinlan, 1988; Kirsner, Milech, \& Standen, 1983 ) tasks. The magnitude of the effects varies widely over tasks, with lexical decision typically exhibiting large effects in latencies and showing effects of response bias on the basis of prime-target relatedness or word familiarity (cf. Balota \& Chumbley, 1984), perceptual identification having large effects in accuracy, and pronunciation having effects in latencies that are small, as compared with lexical decision (see, e.g., Andrews, 1989; Neely, 1991). The present experiments, together with additional work on identity priming and frequency effects (Burt, 1994, 1999), show that the color-naming task exhibits similar but still smaller effects in latencies, as compared with the pronunciation task. That the color-naming task displays small effects is explicable in terms of the task requirements, with subjects being required to ignore word stimuli and respond to color.

There is a compelling similarity among word recognition tasks in relation to nonstrategic priming and frequency effects. All the tasks display the effects and, on available evidence, respond rather similarly to manipulations of relevant variables. For example, nonstrategic priming in lexical decision and naming varies in an orderly way with prime--target SOA (see the review by Neely, 1991). Also, frequency effects in the latter tasks are linear over logarithmic frequency, with larger effects at the lower end of the frequency scale (cf. Seidenberg \& McClelland, 1989). The substantial body of evidence on nonstrategic priming effects and word frequency effects converges on the conclusion that, despite the modulation of such effects by task-related factors, these are core phenomena that are revealing about the processes of word recognition. This conclusion was well supported for word frequency effects in a review by Monsell (1991). The present experiments add to the support for the conclusion, in that they suggest that these facilitatory effects are implicated in word reading. The mechanisms underlying frequency and identity priming effects may not be prelexical, in that they may not affect the retrieval of a word's representation from lexical memory. For example, they may affect hypothesized postaccess orthographic checks (Norris, 1986). Nevertheless, the generality of the effects over tasks supports their importance in word recognition, if not necessarily on lexical access.

Within the Warren noncolor word Stroop task, facilitatory effects on word recognition must be understood in terms of how they modulate ongoing processes leading to the color-naming response. It is assumed that, for the university students who participated in the present experiments, word reading is a highly practiced skill. Furthermore, as in the conventional Stroop task, subjects cannot spatially separate attention to the color from attention to the word and, consequently, are assumed to read the word 
during preparation of their color-naming response. Thus, the small facilitation of color naming that is observable when familiarity or a priming manipulation allows for faster or easier processing of the base word may be understood in terms of the combined processing load for the tasks of word reading and color naming.

To the extent that word reading consumes fewer resources or requires a statutory allocation of resources for a shorter period, more resources may be available for the primary task of color naming. Thus, a preliminary account of the facilitation of color naming reported here is that facilitation of word processing yields an increase in availability of resources, which allows for faster color naming. An implication of this view is that increases in the difficulty of or time required for word recognition should increase color-naming latencies. For example, longer words are predicted to have longer color-naming latencies than short words. Conversely, manipulations that allow subjects to ignore the base word or letter string may facilitate color naming. Thus, Bakan and Alperson (1967) found a decrease in color-naming latency with decreasing pronounceability of nonwords, and Gumenik and Glass (1970) found that reducing the legibility of words (by masking) attenuated color-naming interference.

\section{Conclusion}

The noncolor word Stroop task, like the standard Stroop task, induces proficient readers to divide attention between word reading and color naming. Manipulations in semantic priming arrangements that facilitate word recognition, without the recruitment of attention toward the target and prime words, typically facilitate color naming in the noncolor word Stroop task. The basis of this facilitation may be an increase in the availability of processing resources for color naming. Manipulations in semantic priming that foster the diversion of processing resources to meaning relationships among words typically interfere with color naming. The basis of this interference may be an increase in response competition produced by an on-line increase in the activation accruing in the representation of the target or the prime.

\section{REFERENCES}

ANDREWs, S. (1989). Frequency and neighborhood effects on lexical access: Activation or search? Journal of Experimental Psychology: Learning, Memory, \& Cognition, 15, 802-814.

BAKAN, P., \& ALPERSON, B. (1967). Pronounceability, attensity, and interference in the color-word test. American Journal of Psychology, 80, 416-420.

Balota, D. A., \& Chumbley, J. I. (1984). Are lexical decisions a good measure of lexical access? The role of word frequency in the neglected decision stage. Journal of Experimental Psychology: Human Perception \& Performance, 10, 340-357.

BECKER, C. A. (1979). Semantic contexts and word frequency effects in visual word recognition. Journal of Experimental Psychology: Human Perception \& Performance, 5, 252-259.

BURT, J. S. (1994). Identity primes produce facilitation in a colour naming task. Quarterly Journal of Experimental Psychology, 47A, 957. 1000 .
BURT, J. S. (1999). Visual and auditory identity priming in color naming. Manuscript in preparation.

Burt, J. S., Walker, M. B., Humphreys, M. S., \& Tehan, G. (1993). Associative priming in perceptual identification: Effects of primeprocessing requirements. Memory \& Cognition, 21, 125-137.

Cohen, J. D., Dunbar, K., \& McClelland, J. L. (1990). On the control of automatic processes: A parallel distributed processing account of the Stroop effect. Psychological Review, 97, 332-361.

CoHEn, J. [D.], \& Huston, T. (1994). Progress in the use of interactive models for understanding attention and performance. In C. Umiltà \& M. Moscovitch (Eds.), Attention and performance XV: Conscious and nonconscious information processing ( $\mathrm{pp}$. 453-476). Cambridge, MA: MIT Press, Bradford Books.

Cohen, J. D., Schreiber, D., \& McClelland, J. L. (1992). A parallel distributed processing approach to automaticity: Views and varieties of automaticity [Special issue]. American Journal of Psychology, 105, 239-269.

Conrad, C. (1974). Context effects in sentence comprehension: A study of the subjective lexicon. Memory \& Cognition, 2, 130-138.

Davelaar, E., Coltheart, M., Besner, D., \& Jonasson, J. T. (1978). Phonological recoding and lexical access. Memory \& Cognition, 6, 391-402.

DE GROOT, A. M. B. (1985). Word-context effects in word naming and lexical decision. Quarterly Journal of Experimental Psychology, 37A, 281-297.

DEN HEYER, K. (1985). On the nature of the proportion effect in semantic priming. Acta Psychologica, 60, 25-38.

Dosher, B. A., \& CORBETT, A. T. (1982). Instrument inferences and verb schemata. Memory \& Cognition, 10, 531-539.

FISCHLER, I. (1977). Associative facilitation without expectancy in a lexical decision task. Journal of Experimental Psychology: Human Perception \& Performance, 3, 18-26.

Forster, K. I. (1976). Accessing the mental lexicon. In R. J. Wales \& E. C. T. Walker (Eds.), New approaches to language mechanisms (pp. 257-287). Amsterdam: North-Holland.

Forster, K. I., \& DAVIS, C. (1984). Repetition priming and frequency attenuation in lexical access. Journal of Experimental Psychology: Learning, Memory, \& Cognition, 10, 680-698.

Forster, K. I., \& CHAMBERS, S. M. (1973). Lexical access and naming time. Journal of Verbal Learning \& Verbal Behavior, 12, 627-635.

GuMENIK, W. E., \& Glass, R. (1970). Effects of reducing the readability of the words in the Stroop color-word test. Psychonomic Science, 20, 247-248.

HaYs, W. L. (1981). Statistics (3rd ed.). New York: Holt, Rinehart \& Winston.

Henik, A., Friedrich, F. J., \& Kellogg, W. A. (1983). The dependence of semantic relatedness effects upon prime processing. Memory \& Cognition, 11, 366-373.

HeRDMAN, C. M. (1992). Attentional resource demands of visual word recognition in naming and lexical decisions. Journal of Experimental Psychology: Human Perception \& Performance, 18, 460-470.

HUMPHREYS, G. W., BESNER, D., \& QUINLAN, P. T. (1988). Event perception and the word repetition effect. Journal of Experimental Psychology: General, 117, 51-67.

JARED, D., MCRAE, K., \& SeIDENBerg, M. S. (1990). The basis of consistency effects in word naming. Journal of Memory \& Language, 29, 687-715.

KeEFE, D. E., \& NeELY, J. H. (1990). Semantic priming in the pronunciation task: The role of prospective prime-generated expectancies. Memory \& Cognition, 18, 289-298.

KirSNer, K., MileCh, D., \& Standen, P. (1983). Common and modalityspecific processes in the mental lexicon. Memory \& Cognition, 11, 621-630.

KLEIN, G. S. (1964). Semantic power measured through the interference of words with color naming. American Journal of Psychology, 527, 576-588.

KuČEra, H., \& FranCIS, W. N. (1967). Computational analysis of present-day American English. Providence, RI: Brown University Press. 
LoRCH, R. F., JR., Balota, D. A., \& STAMm, E. G. (1986). Locus of inhibition effects in the priming of lexical decisions: Pre- or postlexical access? Memory \& Cognition, 14, 95-103.

MACLeod, C., \& Rutherford, E. M. (1992). Anxiety and the selective processing of emotional information: Mediating roles of awareness, trait and state variables, and personal relevance of stimulus materials. Behaviour Research \& Therapy, 30, 479-491.

MACLEOD, C. M. (1991). Half a century of research on the Stroop effect: An integrative review. Psychological Bulletin, 109, 161-203.

MARCEL, A. (1983). Conscious and unconscious perception: Experiments on visual masking and word recognition. Cognitive Psychology, 15, 195-237.

MATHEWS, A., \& MAcLeod, C. (1985). Selective processing of threat cues in anxiety states. Behaviour Research \& Therapy, 23, 563-569.

MCClain, L. (1983). Color priming affects Stroop interference. Perceptual \& Motor Skills, 56, 643-651.

MCNamara, T. P., \& AlTarRiba, J. (1988). Depth of spreading activation revisited: Semantic mediated priming occurs in lexical decisions. Journal of Memory \& Language, 27, 545-559.

Merrill, E. C., Sperber, R. D., \& McCauley, C. (1981). Difference in semantic encoding as a function of reading comprehension skill. Memory \& Cognition, 9, 618-624.

MEYer, D. E., \& KIERAS, D. E. (1997). A computational theory of executive cognitive processes and multiple task performance: Part 1 . Basic mechanisms. Psychological Review, 104, 3-65.

Mogg, K., Mathews, A., \& Weinman, J. (1989). Selective processing of threat cues in anxiety states: A replication. Behaviour Research \& Therapy, 27, 317-323.

MONSELL, S. (1991). The nature and locus of word frequency effects in reading. In D. Besner \& G. W. Humphreys (Eds.), Basic processes in reading: Visual word recognition (pp. 148-197). Hillsdale, NJ: Erlbaum.

MORTON, J. (1969). Interaction of information in word recognition. Psychological Review, 76, 165-178.

NeELY, J. H. (1977). Semantic priming and retrieval from lexical memory: Roles of inhibitionless spreading activation and limited capacity attention. Journal of Experimental Psychology: General, 106, 226-254.

NeELY, J. H. (1991). Semantic priming effects in visual word recognition: A selective review of current findings and theories. In D. Besner \& G. W. Humphreys (Eds.), Basic processes in reading: Visual word recognition (pp. 264-336). Hillsdale, NJ: Erlbaum.

NEILL, W. T. (1978). Decision processes in selective attention: Response priming in the Stroop color-word task. Perception \& Psychophysics, 23, 80-84.

Nelson, D. L., McEvoy, C. L., \& Schreiber, T. (1992). The University of South Florida word association, rhyme and word fragment norms. Unpublished manuscript.

NoRRIs, D. (1986). Word recognition: Context effects without priming. Cognition, 22, 93-136.

ODEN, G. C., \& SPIRA, J. L. (1983). Influence of context on the activation and selection of ambiguous word senses. Quarterly Journal of Experimental Psychology, 35A, 51-64.

Palermo, D. S., \& Jenkins, J. J. (1964). Word association norms:
Grade school through college. Minneapolis: University of Minnesota Press.

PARKIN, A. J. (1979). Specifying levels of processing. Quarterly Journal of Experimental Psychology, 31, 175-195.

PARKIN, A. J. (1983). Phonological recoding in lexical decision: The influence of pseudohomophones. Language \& Speech, 26, 81-90.

Postman, L. (1970). The California norms: Association as a function of word frequency. In L. Postman \& G. Keppel (Eds.), Norms of word association (pp. 241-320). New York: Academic Press.

Seidenberg, M. S., \& MCClelland, J. L. (1989). A distributed, developmental model of word recognition and naming. Psychological Review, 96, 523-568.

SheLTON, J. R., \& MARTIN, R. C. (1992). How semantic is automatic semantic priming? Journal of Experimental Psychology: Learning, Memory, \& Cognition, 18, 1191-1210.

Smith, L. C., Briand, K., Klein, R. M., \& den Heyer, K. (1987). On the generality of Becker's verification model. Canadian Journal of Psychology, 41, 379-386.

Smith, M. C., Theodor, L., \& Franklin, P. E. (1983). The relationship between contextual facilitation and depth of processing. Journal of Experimental Psychology: Learning, Memory, \& Cognition, 9, 697. 712.

STROOP, J. R. (1935). Studies of interference in serial verbal reactions. Journal of Experimental Psychology, 18, 643-662.

Tanenhaus, M. K., Flanigan, H. P., \& Seidenberg, M. S. (1980). Orthographic and phonological activation in auditory and visual word recognition. Memory \& Cognition, 8, 513-520.

Thomson, D. M., Meredith, S. G., \& Browning, C. (1976). Monash free association norms. Melbourne: Monash University.

VANVOORHIS, B. A., \& DARK, V. J. (1995). Semantic matching, response mode, and response mapping as contributors to retroactive and proactive priming. Journal of Experimental Psychology: Learning, Memory, \& Cognition, 21, 913-932.

WARREN, R. E. (1972). Stimulus encoding and memory. Journal of Experimental Psychology, 94, 90-100.

WARREN, R. E. (1974). Association, directionality and stimulus encoding. Journal of Experimental Psychology, 102, 151-158

Watts, F. N., McKenna, F. P., Sharrock, R., \& Trezise, L. (1986). Colour naming of phobia related words. British Journal of Psychology, 77, 97-108.

WHITNEY, P. (1986). Processing category terms in context: Instantiations as inferences. Memory \& Cognition, 14, 39-48.

Whitney, P., McKay, T., Kellas, G., \& Emerson, W. A. J. (1985). Semantic activation of noun concepts in context. Journal of Experimental Psychology: Learning, Memory, \& Cognition, 11, 126-135.

\section{NOTE}

1. In the present paper, effects of a prime word on color naming will be referred to as priming effects, with specification of the direction (facilitation or interference) where necessary for clarification.

(Manuscript received January 24, 1997 revision accepted for publication March 9, 1998.) 